\title{
Participatory Teaching and Happiness in Developed Nations
}

\author{
Gaël Brulé, Ruut Veenhoven \\ EHERO, Erasmus University of Rotterdam, Rotterdam, The Netherlands \\ Email: brule@ese.eur.nl \\ Received 28 September 2014; revised 18 October 2014; accepted 24 October 2014 \\ Copyright (C) 2014 by authors and Scientific Research Publishing Inc. \\ This work is licensed under the Creative Commons Attribution International License (CC BY). \\ http://creativecommons.org/licenses/by/4.0/ \\ c) (i) Open Access
}

\begin{abstract}
Average happiness differs considerably across nations. Much of this difference is in societal development, but average happiness differs also among developed nations. Much of that latter difference seems to be due to cultural factors and education is a main carrier of these. In that context we explored the effect of teaching styles on happiness. In a first study on the general public in $\mathbf{3 7}$ developed nations we found that people feel happier in the nations where participatory teaching prevailed. Much of this difference can be explained by the effect of teaching style on psychological autonomy. Participatory teaching fosters autonomy and autonomy adds to happiness. In a second study among high school pupils we found no correlation between average happiness and dominant teaching style in the nation, which fits the explanation that the effect of participatory teaching is in personality formation, with the consequences for happiness of which manifest in adulthood.
\end{abstract}

\section{Keywords}

Participatory Teaching, Happiness, Life Satisfaction, Vertical Teaching, Horizontal Teaching

\section{Introduction}

Interest in happiness has grown during the last decades, both among individual citizens and policy-makers. The rising interest among individuals can be seen in the soaring sales of "how-to-be-happy" books and the growing life-coach industry. The interest among policy-makers is most manifest in Bhutan, which aims at "Gross National Happiness" and now in the UK where the call for "greater happiness for a greater number" is explicitly on the political agenda. In parallel, research into conditions that promote happiness has taken off. To date there are some 7000 scientific publications in the Bibliography of Happiness (Veenhoven, 2012a) with a yearly growth rate of about 5\% (Veenhoven, 2011: Section 3). 


\section{Cross National Differences in Happiness}

Part of this research is about happiness in nations and has revealed great differences, for instance, on a 0 to 10 scale average happiness was 8.3 in Denmark in 2010 and only 3.0 in Zimbabwe. All findings of this kind are gathered in the collection "Happiness in Nations", which is part of the World Database of Happiness (Veenhoven, 2012b). These differences in average happiness in nations appear to be consistently related to several societal characteristics, such as economic development, political democracy and female emancipation. These findings are gathered in the report "Findings on Happiness and Conditions in One’s Nation” (Veenhoven, 2012c). Together these national characteristics explain about $75 \%$ of the observed differences in average happiness across nations (Veenhoven, 2010). Recent overviews of this research field can be found with Diener and Suh (2000) and Helliwell et al. (2012).

\section{Limited View on Cultural Determinants}

The differences in average happiness in nations have been explained mainly using social structural variables, for which considerable international statistics are available. By lack of data, cultural explanations have received less attention. Still there are indications that culture does matter. Inglehart and Klingemann (2000) has found strong correlations between happiness and value patterns in nations, people being happier in nations where individualistic values prevail. Likewise Senik (2011) has highlighted the influence culture has on happiness on immigrants in France whereas Brulé and Veenhoven (2012) showed how history influenced the average level of satisfaction.

\section{Focus on Education}

In this paper we add to this strand of research and look into the effects of education on happiness in nations. Education is likely to be a powerful determinant of happiness, since we spend a substantial part of our life in school. Together with family and religion, education is one of the main mechanisms for transmitting culture.

A special reason for focusing on education is that an earlier study showed that a considerable part of the difference in average happiness across developed nations is in the psychological autonomy of its citizens. Exemplary cases are Finland and France, with the Fins being both more autonomous and happier than the French (Brulé \& Veenhoven 2014). This calls for an explanation of this difference in "national character".

In the above mentioned paper we have considered possible historical causes of present day differences in average happiness in nations, such as feudalism having affected the south of Europe more than the north. Such echoes of the past sustain only if reproduced in the present and in this context we explore in this paper whether the observed differences in self-direction are reproduced in school education. In our view the difference is not in what pupils learn in school, since curricula are quite similar in developed nations. We rather look at how pupils learn, since teaching practices involve much implicit learning. In that context we focus in particular on "participatory teaching”. We expect that participatory teaching fosters psychological autonomy, which in its turn fosters happiness.

\section{Plan of This Paper}

Below we will start by explaining what we mean by "happiness" and how average happiness in nations is assessed (Section 1.1). Next, we will consider teaching styles and how these are measured. We construct an index of "participatory teaching" and inspect how the scores on that index differ across nations (Section 1.2).

On this basis we will then explore the relation between happiness and participatory teaching in nations (Section 2). For reasons of comparability we have limited ourselves to comparing developed societies. We used data on teaching in 37 nations and we checked whether differences in this kind of teaching correspond to differences in average happiness in nations, both in the general public (Study 1) and among secondary school pupils (Study 2). We find a strong correlation in Study 1, but not in Study 2.

Having established these basic facts, we go on to explore a possible causal path, and test the hypothesis that participatory teaching adds to happiness though its effect on psychological autonomy (Section 4). In that context we explore the link between participatory teaching and freedom (Section 4.1), we then investigate its link with happiness (Section 4.2) and explain why participatory teaching influences happiness for adults and not for teenagers (Section 4.3). Finally, we acknowledge the limitations of our study (Section 5).

\subsection{Happiness}

What is "happiness" precisely? How can we measure happiness in nations? Does happiness differ across nations?

Concept

This paper is about happiness in the sense of "subjective well-being”. Following Veenhoven (1984) we define 
happiness as the degree to which someone evaluates the overall quality of his or her present life-as-a-whole positively. In other words, how much one likes the life one lives.

\section{Measurement}

Happiness is something we have in mind and things we have in mind can be assessed using questioning. Questions on happiness can be framed in many ways, directly or indirectly, using single or multiple items. An overview of acceptable questions is available in the collection "Measures of Happiness" of the World Database of Happiness (Veenhoven, 2012d). Several of these measures have been used in survey studies among the general population in nations. As noted above this has revealed wide differences in average happiness, of which about $75 \%$ can be explained by societal characteristics such as economic development and political democracy.

\subsection{Participatory Teaching}

As noted, we focused not on what pupils learn in school, but on how they learn. We looked for teaching practices likely to influence self-direction.

\section{Concept}

We have built on work by Algan, Cahuc and Shleifer (2013) who distinguishes two types of teaching: vertical teaching and horizontal teaching. The former refers to lecturing and note-taking, while the latter is based on work in groups and cooperation among students. Below we describe how these matters are measured and how we combined the results to obtain an index of "participatory" teaching.

\section{Measurement}

Two studies have been done to assess teaching practices across nations and the results show considerable differences.

The Civic Education Study (CES) is a survey of pupils and teachers in the eighth grade, in 25 countries $^{1}$ in 1999. Pupils are teenagers around 13 - 14 years old. The survey was run by the International Association for the Evaluation of Educational Achievement (IEA). Both pupils and staff completed questionnaires. The pupils from each country were selected in a two-step process; first by random selection of schools and then by random selection of pupils in the selected schools. The teachers and school principals of the selected schools also completed a questionnaire.

The teacher questionnaire involved questions about teaching practices: In your class, a) How often do students work in groups? b) How often do students work on projects? c) How often do students study textbooks? d) How often do students participate in role play, e) How often does the teacher lecture? f) How often does the teacher include discussions? g) How often does the teacher ask questions? The answers were given the values 1 never, 2 sometimes, 3 often and 4 very often.

Following Algan's method, we focused on the two ends of the spectrum of teaching practices from the CES, "teacher lectures" on one side and "students work in groups" on the other. The former indicates vertical teaching practices, the latter horizontal teaching. These dimensions have also been referred to as respectively "teacher centered" and "student centered" education. A "z-score" was calculated, ranging from 0 for the country with the most vertical teaching (France) to 1 for the country with the most horizontal teaching (Sweden).

The Trends in International Mathematics and Science Study (TIMSS) is a multi-country comparative test of student cognitive achievement in mathematics and science, conducted in 1995 by the IEA, the same international consortium that constructed the CES database. The TIMSS also contains information about grade 8 students and covers 37 countries $^{2}$. Students, school principals and teachers were questioned using a representative sample of schools and students from the different nations studied. Teaching practices were measured using the individual student surveys conducted in all classrooms in each of the sampled schools.

The survey covers class subjects including: Mathematics, science, biology, chemistry and the earth sciences. We focused on the teaching practices in mathematics, as this allowed us to make comparison between a maximum number of countries. Additionally, the focus on mathematics was expected to be a good case for comparing how pupils learn, because of the great similarity in what is being learned.

The questions on teaching practices used in our analysis were: "In school, how often do you do these things?

\footnotetext{
${ }^{1}$ Australia, Bulgaria, Chile, Cyprus, Czech Republic, Denmark, England, Estonia, Finland, Germany, Greece, Hungary, Italy, Latvia, Lithuania, Norway, Poland, Portugal, Romania, Russian Federation, Slovak Republic, Slovenia, Sweden, Switzerland and the United States.

${ }^{2}$ Australia, Austria, Belgium, Bulgaria, Canada, Czech Republic, Denmark, Finland, France, Germany, Greece, Hungary, Iceland, Indonesia, Iran, Ireland, Israel, Italy, Japan, Korea, Latvia, Lithuania, Netherlands, Norway, Portugal, Romania, Russia, Singapore, Slovakia, Slovenia, Spain, Sweden, Switzerland, Turkey, United Kingdom and the United States.
} 
Copy notes from the board during the lessons? Work together in pairs and small groups in class?” The answers ranged from 1 all the time, 2 often, 3 sometimes, to 4 never. A z-score was calculated, ranging from 0 , the country with the most vertical teaching (Romania) to 1 , the country with the most horizontal teaching (Switzerland).

\section{Pooled Data}

In order to have the highest number of countries we combined the ratings obtained in the two studies, the TIMSS and the CES. When both studies covered the same country, an average score was used.

\section{Index of Participatory Teaching in Nations}

We combined the scores for nations on horizontal and vertical teaching, by subtracting the latter from the former. The resulting index indicates the extent to which horizontal teaching dominates in a country. We call it the index of "participatory teaching". The results for 37 nations are shown in Table 1.

\begin{tabular}{|c|c|}
\hline Switzerland & 0.95 \\
\hline Danmark & 0.87 \\
\hline Sweden & 0.85 \\
\hline Iceland & 0.85 \\
\hline Netherlands & 0.85 \\
\hline United Kingdom & 0.84 \\
\hline Canada & 0.82 \\
\hline Norway & 0.74 \\
\hline United States & 0.72 \\
\hline Slovak Republic & 0.72 \\
\hline Lithuania & 0.71 \\
\hline Australia & 0.70 \\
\hline Poland & 0.64 \\
\hline Germany & 0.64 \\
\hline Israel & 0.58 \\
\hline Slovenia & 0.56 \\
\hline Latvia & 0.53 \\
\hline Belgium & 0.51 \\
\hline Finland & 0.51 \\
\hline Hong Kong & 0.49 \\
\hline Estonia & 0.48 \\
\hline Portugal & 0.47 \\
\hline Spain & 0.47 \\
\hline Italy & 0.44 \\
\hline Bulgaria & 0.37 \\
\hline Hungary & 0.34 \\
\hline Czesc Republic & 0.33 \\
\hline Austria & 0.28 \\
\hline Korea, Republic of & 0.27 \\
\hline Romania & 0.27 \\
\hline Cyprus & 0.26 \\
\hline Turkey & 0.21 \\
\hline Greece & 0.19 \\
\hline Russian Federation & 0.18 \\
\hline Japan & 0.10 \\
\hline Ireland & 0.06 \\
\hline France & 0.00 \\
\hline
\end{tabular}




\section{Differences across Nations}

Looking at Table 1 it can be seen that France is the country where teaching is the least participatory and that teachers use the most participatory methods in Switzerland. The lows score of France fits a wider south European pattern and is possibly enhanced by the selective nature of the French schooling system. The high score of Switzerland fits a north-western European pattern and is possibly fostered by the high degree of direct democracy in the Swiss political system.

\section{Not a Matter of Money}

Do these differences in teaching style reflect cultural differences, or are they a by-product of financial investment in education? This could be the case if vertical teaching is cheaper than horizontal teaching. There is indeed a correlation between "participatory teaching" and the percentage of GDP spent in education, however it is small $(r=+.24)$ and a look at the scatter plot on Figure 1 shows considerable divergence: For instance participatory teaching is less common in France and Spain than in the Netherlands, while these countries spend equally on education (11\% of GDP). Ireland scores the second lowest on participatory teaching, although it spends the most on education.

\section{Study 1: Participatory Teaching and Happiness in the General Public in Developed Nations}

Are these differences in participatory teaching in nations related to happiness? We explored this in a comparison of average happiness in the general public of 27 developed nations.

\subsection{Method}

\section{Cases}

For reasons of comparability and availability of data, we restricted our data to that for developed nations. We consider a nation as "developed" if the average annual income per head is $\$ 20,000$ or more. Of the 37 nations for which we have data on both participatory teaching and happiness 27 fit this criterion. These nations are: Austria, Australia, Belgium, Canada, Cyprus, Czech Republic, Denmark, Finland, France, Germany, Greece, Hong Kong, Iceland, Ireland, Israel, Italy, Japan, the Netherlands, Norway, Portugal, Slovenia, South Korea, Spain, Sweden, Switzerland, United Kingdom, and the United States.

\section{Measures}

Happiness in these nations is measured using the average response to the question: "Taking all together, how satisfied or dissatisfied are you with your life as a whole these days?" Please answer by ticking a number between 0 to 10, where 0 stands for most "dissatisfied" and 10 for most "satisfied". In the World Database of Happiness this question is classified as a measure type O-SLW-c-sq-n-11-a (Veenhoven, 2012d). Responses to this question and equivalent ones are gathered in the collection "Happiness in Nations" of the World Database of Happiness (Veenhoven, 2011b).

Participatory teaching in nations is measured using the prevalence of horizontal teaching over vertical teaching (cf. Section 1.2).

\subsection{Results}

We started with a scatter plot of participatory teaching (horizontal) against and happiness (vertical) (See Figure 1). We see a linear pattern of correlation, in which Switzerland stand out as the country with most participatory teaching and the highest happiness and Japan as a case of little participatory teaching and low happiness. Ireland is an outlier in this pattern, with a relatively high level of happiness in spite of little participatory teaching.

Given this linear pattern it makes sense to compute a correlation: $r=+.60^{3}$. To appraise the strength of this correlation we compared it with other variables in the same nation set. The correlation between happiness and percentage of GDP spent on education was +.30 , which means that from a happiness perspective, teaching methods are more important for happiness than the amount of money a nation invests in education. The correlation between happiness and participatory teaching is also stronger than that for happiness and income inequality

\footnotetext{
${ }^{3}$ Avoiding common practice we do not report statistical significance of correlations among macro variables. Tests of significance inform us about the probability that a relationship found in a random sample also exists in the population from which that sample is drawn. This set of countries was not a random sample and for this reason significance testing makes no sense.
} 


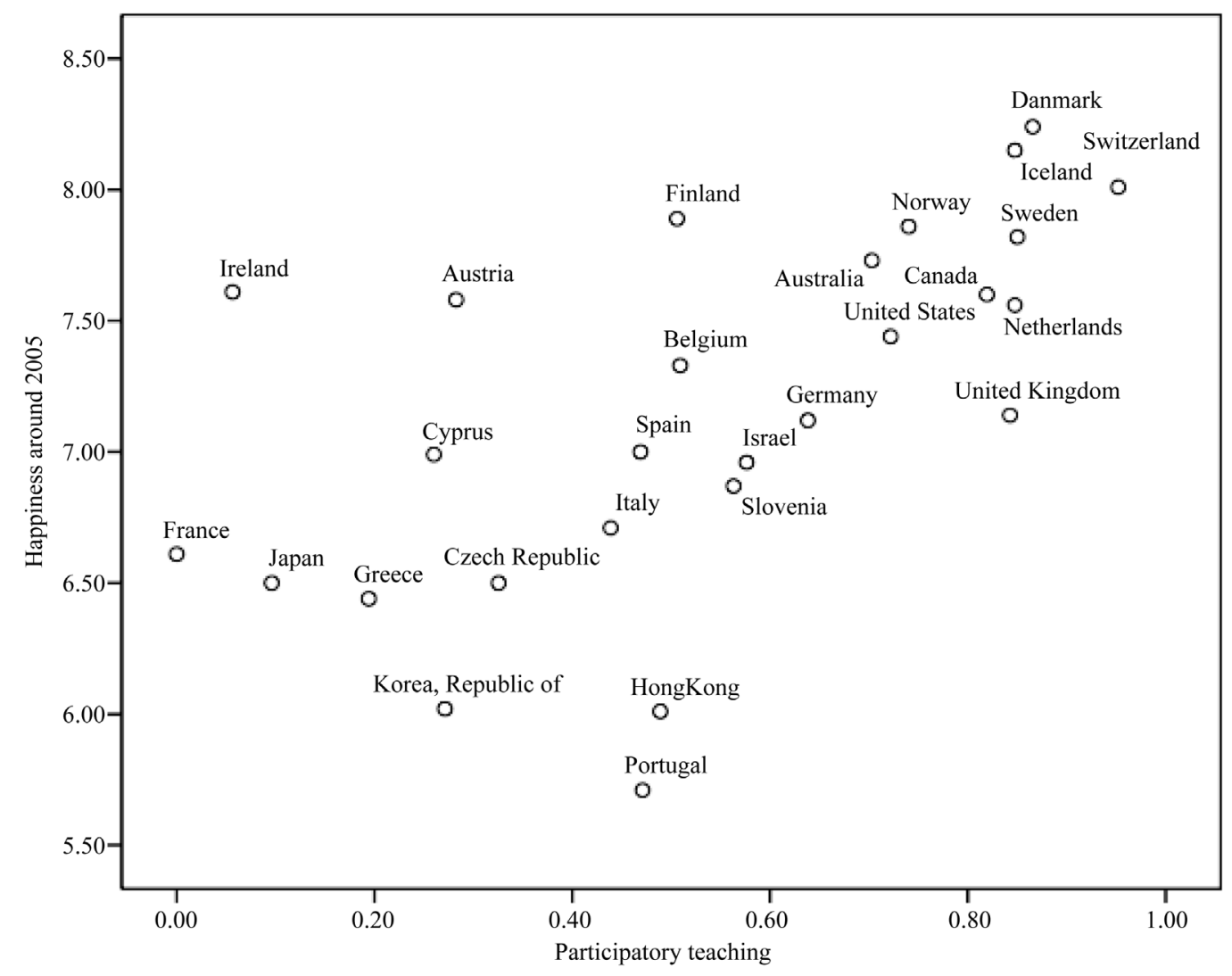

Figure 1. Happiness and participatory teaching in 27 developed nations: Scatter plot.

(-.25) or public health expenditures (+.37). The strength of the correlation for happiness and participatory teaching is comparable to institutional factors such as gender equality $(+.60)$ and government effectiveness (+.73). So we have really hit on something important.

Analyzing horizontal and vertical teaching separately does not change the picture. Horizontal teaching is positively correlated with happiness while vertical teaching is negatively correlated. Separate analysis of the two datasets also did not change the picture. Participatory teaching correlates positively with happiness in TIMSS data $(+.56)$ and in CES data $(+.55)$.

Next to these bi-variate analyses, we checked for possible spuriousness in the correlation, controlling for variables that are likely to produce an inflated correlation, without wiping away true correlation ${ }^{4}$. Since wealth might be such a factor and there are still differences in affluence in this set of developed nations, we controlled buying power per head, which reduced the correlation to +.43 . We also controlled average IQ as an indicator of the quality of the educational system and the murder rate as an indicator of order in society. The partial correlations are respectively +.63 and +.54 which suggests that there is a considerable correlation between participatory teaching and average happiness in developed nations.

\section{Study 2: Participatory Teaching and Happiness among High School Pupils in Nations}

\subsection{Method}

We also assessed the relationship between participatory teaching and happiness in another population, using high-school pupils instead of the general public. Data on happiness were taken from the Health Behaviour in School-aged Children survey (HBSC). In this study, data has been collected about health, health behaviours and life satisfaction among 11, 13 and 15 year olds pupils. The units of sampling are school classes and sample sizes

${ }^{4}$ Contrary to common practice we did not control for all other correlates of happiness in nations. Given the causal interrelations, that would be like throwing away the baby with the bathwater. 
are 1550 per age group in nations (Currie et al., 2008).

Cases

Data on both happiness of high-school pupils and participatory teaching are available for 22 developed countries. The countries included in the dataset were: Austria, Belgium, Canada, Czech Republic, Denmark, Finland, France, Germany, Greece, Iceland, Ireland, Israel, Italy, the Netherlands, Norway, Portugal, Slovenia, Spain, Sweden, Switzerland, United Kingdom and the United States.

\section{Measures}

In the HBSC studies happiness is measured using responses to the question: "Here is a picture of a ladder, suppose that the top represents the best possible life and the bottom the worst possible life. Where on this ladder would you place your current life?” (0 worst possible, 10 best possible). This question differs from the question used in study 1 in that it invites respondents to make a more cognitive evaluation of their life. In the world Database of Happiness this question is classified as a measure of "contentment" and coded C-BW-c-sq-l-11-c (Veenhoven, 2012d). Participatory teaching was measured in the same way as in study 1.

\subsection{Results}

In this case we saw no correlation between average happiness and participatory teaching in nations: $\mathrm{r}=+.02$. Separate analysis of horizontal and vertical teaching confirms this correlation as both correlations are very low; the correlation between average happiness and horizontal teaching is -0.03 while correlation between average happiness and vertical teaching is -0.15 .

\section{Explanations}

Why is the average citizen happier in nations where participatory teaching prevails? Below we will argue that participatory teaching enhances freedom, psychological freedom in particular. In its turn freedom adds to happiness and, especially to happiness in a modern multiple-choice society. Why then are high-school pupils no happier in nations where participatory teaching prevails? Below we will argue that the main effect on happiness is found in long-term personality formation, rather than in short-term enjoyment of school hours.

\subsection{Participatory Teaching Prepares for Freedom}

Much of the differences in average happiness across nations can be explained by freedom, the more freedom society allows, the happier citizens typically are (Veenhoven, 2008). Below we will argue that participatory teaching is likely to foster one aspect of freedom in particular, that is, psychological freedom, also called "psychological autonomy”. To that end we will first discuss the concept of freedom and how it affects happiness.

\section{Aspects of Freedom}

Bay (1970) distinguishes three aspects of freedom: social freedom, psychological freedom and potential freedom. Social freedom is about the opportunity to choose and denotes the absence of restrictions imposed by other people. Psychological freedom is about the capability to choose and denotes an absence of inner restrictions. Potential freedom is about access to information on possible options for choice.

In an earlier paper we presented indicators of each of these kinds of freedom in nations and a factor analysis confirmed this conceptualization (Brulé \& Veenhoven, 2014). For the purpose of this study we repeated that analysis for the 27 nations at hand here. We use different indicators that neatly load on three distinct factors that fit Bay's distinction between three kinds of freedom.

\section{How Freedom Can Enhance Happiness}

In a recent paper, the links between the three types of freedom and happiness were shown (Brulé \& Veenhoven, 2014). Each type of freedom will add to the chance that one lives a life one wants to live and that one can change one's way of life if it is no longer satisfying. Although there are costs to freedom, such as choice stress, the positive effects appear to dominate (Veenhoven, 2000, 2008).

In this context social freedom enlarges an individual's opportunities to choose, for instance if choice of a spouse is not limited to one of the same religion, there is a better chance of finding one that really fits you. Opportunities can only be used if one is aware of them, and this is where potential freedom comes in. In the exam- 
ple of marrying someone from another religion, there can be misinformation about the consequences of mixed marriage, such as the contention that children from such marriages lack a moral orientation and often end up in jail. Even if one is well informed one may still lack the guts to choose and that is what psychological freedom is about. In the above example you may forsake your real love and settle for a marriage of reason in order to avoid rejection by your mother.

\section{How Participatory Teaching Can Enhance Freedom}

Participatory teaching may affect freedom in various ways. One can expect that citizens in societies where participatory teaching prevails press more for freedom practicing in their political behaviour what they have learned in school. As such participatory teaching could foster social freedom in nations. Participatory teaching also adds to an individual's potential freedom in that it trains information seeking and creates more awareness of informational manipulation. Participatory teaching is also likely to foster psychological freedom, which will add to the chance that citizens use opportunities to choose, and resist pressures to conform.

\subsection{Test of the Causal Chain: Participatory Teaching $\rightarrow$ Freedom $\rightarrow$ Happiness}

We checked this explanation in a further analysis of Study 1. As a first step we assessed the correlations of the three freedom variant with participatory teaching and average happiness (See Table 2).

Two very strong correlations appear between participatory teaching and psychological freedom $(r=+.69)$ and between psychological freedom and happiness (+.59), which fits the explanation that participatory teaching adds to happiness by fostering psychological autonomy. Yet the data also show effects through other variants of freedom. In order to assess the independent effect of each kind of freedom we computed partial correlations, which are shown in right hand column of Table 2.

Looking at these partial correlations, we can see that the correlation between psychological freedom and happiness (+.59) almost disappears when controlling for participatory teaching (+.17). Likewise, we can see in Table 3 that the relationship between participatory teaching and happiness in nations (+.60) is halved when psychological freedom (+.32) is partialled out. Conversely, the link between participatory teaching and psychological freedom (+.69) is little reduced when happiness is controlled (+.52).

We can also see that social freedom is involved in the link between participatory teaching and happiness as the partial correlation is the same as in the case of psychological freedom (+.32). Participatory teaching has almost no influence in the link between social freedom and happiness as the partial correlation (+.55) is almost the same as the zero order correlation (+.62). The partial correlation between participatory teaching and happiness $(+.45)$ is higher than in the case of psychological freedom. Participatory teaching has no influence on the correlation between potential freedom and happiness.

In this analysis, psychological freedom appears to be the main mediator in the relation between participatory teaching and happiness in nations. Participatory teaching seems to enhance psychological freedom and social freedom, which are both strongly correlated to happiness. To verify this hypothesis, we performed a path analysis. Results are presented in Figure 2.

In this analysis we see again that participatory teaching adds to happiness through its effect on psychological freedom in the first place. In this case the influence of potential freedom is a bit higher, while the influence of social freedom is lower than in the earlier partial correlation analysis. The difference is probably in the 5 cases lost in this analysis. Though the model fit could be better, the pattern of links is confirmed.

\subsection{Why Is There No Correlation among High School Pupils?}

The effect of participatory teaching on happiness appeared to be strong in Study 1 among adults in 27 nations,

Table 2. Correlations of freedom with participatory teaching and happiness in 27 developped nations.

\begin{tabular}{cccc}
\hline & & \multicolumn{2}{c}{ Correlation with happiness } \\
\hline Freedom & Correlation with participatory teaching & Zero order & Participatory teaching partialled out \\
\cline { 3 - 4 } Social freedom & +.62 & +.63 & +.55 \\
Psychological freedom & +.69 & +.59 & +.17 \\
Potential freedom & +.42 & +.55 & +.58 \\
\hline
\end{tabular}


Table 3. Correlation of happiness with participatory teaching in 27 developed nations.

\begin{tabular}{lcc}
\hline Zero order correlation & & +.60 \\
\hline \multirow{2}{*}{ Partial correlations controling } & Social freedom & +.32 \\
& Psychological freedom & +.32 \\
+.48 & Potential freedom & +.48 \\
\hline
\end{tabular}

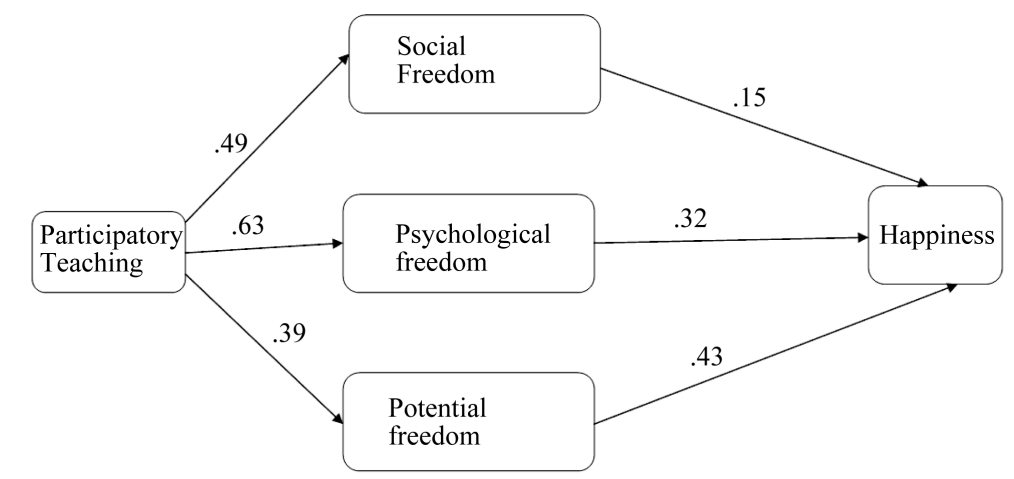

Figure 2. Participatory teaching, freedom and happiness in 27 developed nations: Path analysis.

but non-existent in Study 2 among high school pupils in 22 nations. How can we explain this difference? At first one would expect that the effect of teaching style on happiness to be stronger among those sitting on the school bench.

A methodological explanation might be found in the measure of happiness used. In Study 1 happiness among adults was measured using a question about "life-satisfaction" while in Study 2 high-school pupils rated their life on a ladder ranging from the "best possible" to the "worst possible". The former question taps "overall happiness", while the latter taps the cognitive component of happiness, called "contentment" in Veenhoven (2012d). Is average "contentment" less sensitive to participatory teaching and freedom? We checked in Study 1 among general population samples, for which data on contentment are also available. We found the link between participatory teaching and contentment for adults to be in the same range as for life satisfaction (+.55). Possibly the question on contentment is not the most appropriate for youngsters, who typically have no crystallized ideas of what the best possible life is like. High-school pupils will be more aware of how happy they feel most of the time, so future studies on high school pupils should use affective measures of happiness. For the time being we do not know whether this will make a difference to the results we get.

A more substantive explanation is that there is little difference in freedom among high-school pupils. At that age there is not much to choose to do and one's choices are limited by adults, such as one's parents and teachers. So even if participatory teaching prepares them for freedom, it would make little difference in their present situation and hence have little effect on their happiness.

A related explanation is that the effects of participatory teaching on freedom manifest later in life, when personality has crystallized and when real choices have to be made. In other words, psychological freedom has no use during teenage years, as the number of choices is limited. Participatory teaching is a favourable ground to develop an internal locus of control, and later on, this control orientation favours freedom.

One effect is that inner controlled citizens are more likely to press for social freedom in their society and thus create more opportunity to choose. Another effect is that this psychological mindset will add to the chance that they take advantage of these opportunities to choose and develop a life-style that fits them well. As a result they will be happier.

So it seems that the seeds of participatory teaching flourish only in adulthood in its long-term effects on an individual's psychological freedom. Teenagers reap these fruits later in life.

\subsection{Net Effect of Teaching Style}

The development of psychological autonomy depends on more than just teaching style in school and is particu- 
larly influenced by socialization at home. This begs the question of whether there is any independent effect of teaching style. If not, the correlation between participatory teaching and happiness will disappear when home socialization for independence is controlled. We checked using data of the World Values Survey that involves questions about the importance of things that children can be encouraged to learn at home, one of which is "independence". We computed the percentage of affirmative answers in nations and partialled that variable out ${ }^{5}$. This halved the correlation, but did not wipe it out. This does suggest an independent effect.

\section{Limitations}

It should be noted that the number of nations for which all data is available is fairly limited; a larger number of nations with systematic, reliable data would make the conclusions more robust.

Another limitation is in the cross-sectional nature of this analysis, which can suggest causality, but cannot prove that. Cross-national panel studies could solve that problem, but for the time-being such data is not available.

The data used here are at the macro level of nations. Our explanation assumes effects at the micro-level, in particular that participatory teaching fosters the development of more autonomous personalities, which later in life results in better choices and hence in greater happiness. Though autonomy ranks high as a goal in participatory education, we found no empirical evidence for long-term effects of this kind of teaching on the development of related personality traits such as self-esteem and control orientation. We neither found any individual level data on school environment in youth and happiness in adulthood. So for the time being, we must make do with these findings at the macro level and these suggest a robust effect of participatory teaching on happiness.

\section{Conclusion}

Adults are happier in nations where participatory teaching prevails. The effect of participatory teaching seems to lie in its fostering of freedom in society. Participatory teaching provides a countervailing power against attempts to impose limits on individual's choice and also helps individuals develop the psychological autonomy required to use these opportunities.

\section{References}

Algan, Y., Cahuc, P., \& Shleifer, A. (2011). Teaching Practices and Social Capital. American Economic Journal: Applied Economics, 5, 189-210.

Bay, C. (1970). The Structure of Freedom. Palo Alto: Stanford University Press.

Brulé, G., \& Veenhoven, R. (2012). Why Are Latin Europeans Less Happy? The Impact of Hierarchy, Polyphonic Anthropology-Theoretical and Empirical Cross-Cultural Fieldwork. Rijeka: Intech Europe.

Brulé, G., \& Veenhoven, R. (2014). Freedom and Happiness in Nations. Why the Finns Are Happier than the French. Psychology of Well-Being: Theory Research and Practice, 4, 17. http://dx.doi.org/10.1186/s13612-014-0017-4

Currie, C., Barnekow Rasmussen, V., Currie, D., Gabhainn, S.N., Godeau, E., Morgan, A., Pickett, W., Richter, \& Roberts, C. (2008). Inequalities in Young People's Health: International Report from the HBSC 2005/2006 Survey. Health Policy for Children and Adolescents, No. 5.

Diener, E., \& Suh, E. M. (Eds.) (2000). Culture and Subjective Well-Being. Cambridge: MIT Press.

Helliwell, J. F., Layard, R., \& Sachs, J. (2012). World Happiness Report. New York: Earth Institute, Columbia University.

Inglehart, R., \& Klingemann, H. D. (2000). Genes, Culture, Democracy, and Happiness. In: Culture and Subjective WellBeing (pp. 165-183).

Senik, C. (2011). The French Unhappiness Puzzle: The Cultural Dimension of Happiness. Working Paper n2011-34.

Veenhoven, R. (1984). Conditions of Happiness. Dordrecht: Springer. http://dx.doi.org/10.1007/978-94-009-6432-7

Veenhoven, R. (2000). Freedom and Happiness: A Comparative Study in Forty-Four Nations in the Early 1990s. In: Culture and Subjective Well-Being (pp. 257-288).

Veenhoven, R. (2008). Freedom and Happiness: Comparison of 126 Nations in 2006. Legatum Prosperity Workshop, London, 21-22 June 2008.

${ }^{5} \mathrm{~N}=18$. 
Veenhoven, R. (2010). Greater Happiness for a Greater Number: Is that Possible and Desirable? Journal of Happiness Studies, 11, 605-629. http://dx.doi.org/10.1007/s10902-010-9204-z

Veenhoven, R. (2011). World Database of Happiness: Example of a Focused Findings Archive. Working Paper No. 169, German Data Forum RatSWD, February 2011.

Veenhoven, R. (2012a). Bibliography of Happiness. World Database of Happiness, Erasmus University Rotterdam. http://worlddatabaseofhappiness.eur.nl/hap_bib/bib_fp.php

Veenhoven, R. (2012b). Happiness in Nations, World Database of Happiness, Erasmus University Rotterdam. http://worlddatababaseofhappiness.eur.nl/hap_nat/nat_fp.php

Veenhoven, R. (2012c). Findings on Happiness and Conditions on One’s Nation. World Database of Happiness, Erasmus University Rotterdam. http://worlddatabaseofhappiness.eur.nl/hap cor/top sub.php?code=N4

Veenhoven, R. (2012d). Measures of Happiness, World Database of Happiness, Erasmus University Rotterdam. http://worldedatabaseofhappiness.eur.nl/hap_quesr/hqi_fp.htm 
Scientific Research Publishing (SCIRP) is one of the largest Open Access journal publishers. It is currently publishing more than 200 open access, online, peer-reviewed journals covering a wide range of academic disciplines. SCIRP serves the worldwide academic communities and contributes to the progress and application of science with its publication.

Other selected journals from SCIRP are listed as below. Submit your manuscript to us via either submit@scirp.org or Online Submission Portal.
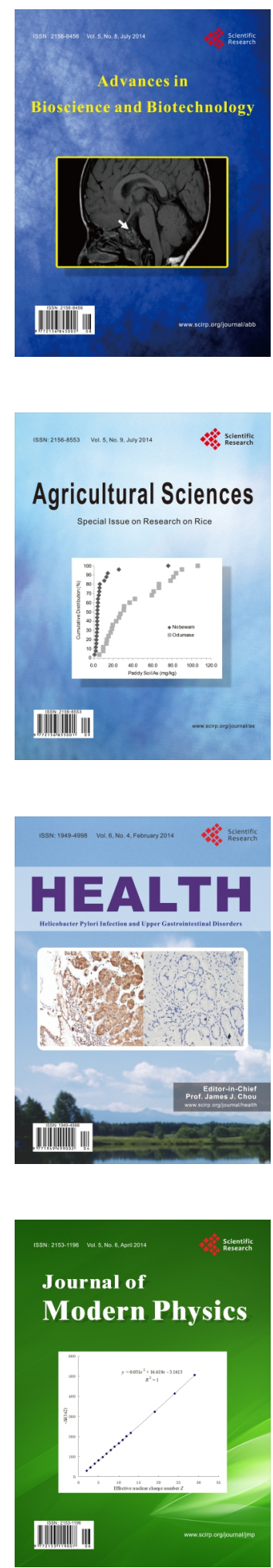
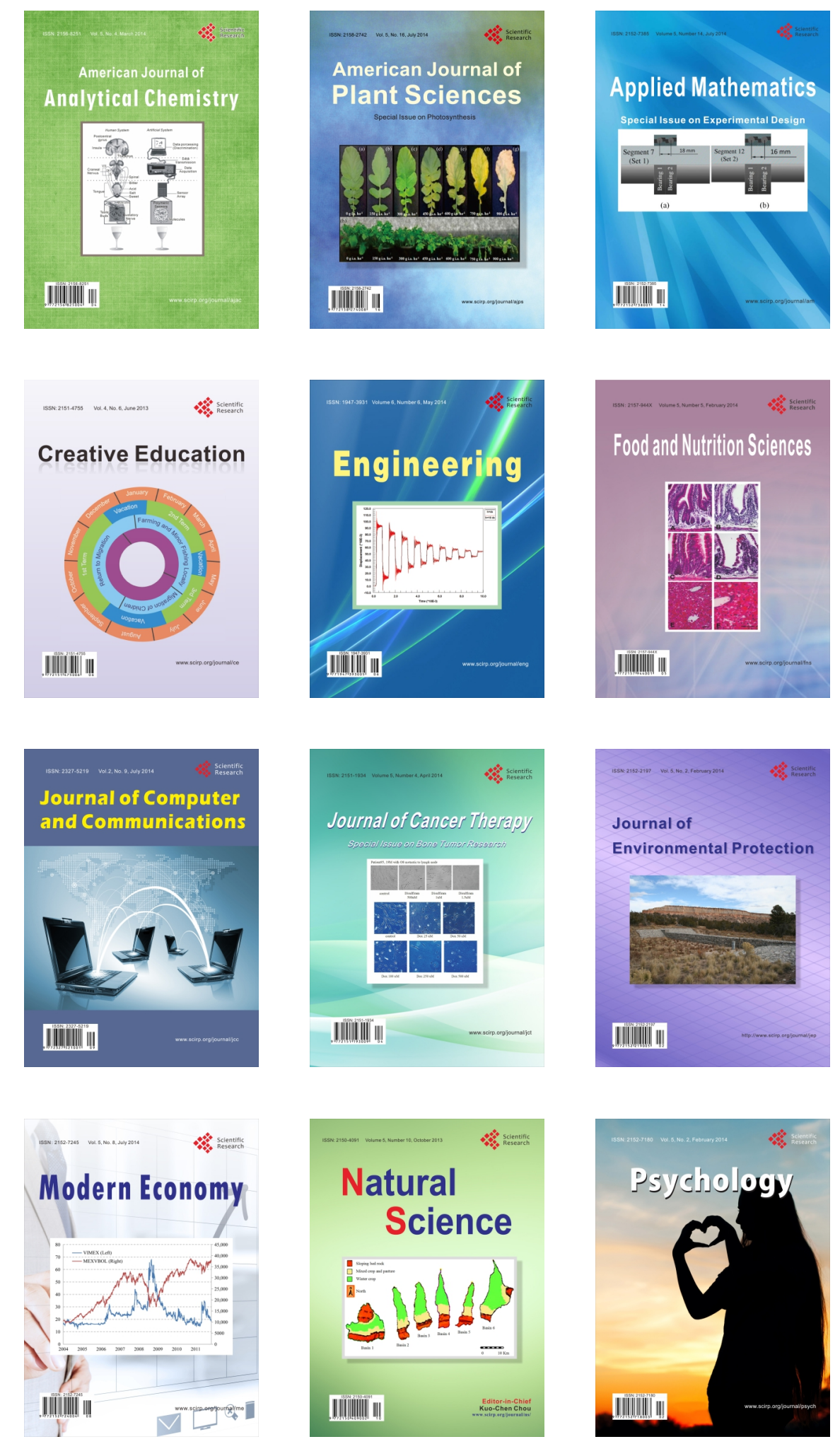